\title{
Static structural analysis of rolling ball bearing
}

\author{
Peter Šulka ${ }^{1, *}$, Alžbeta Sapietová ${ }^{1}$, Vladimír Dekýš ${ }^{1}$, Milan Sapieta ${ }^{1}$ \\ ${ }^{1}$ Department of Applied Mechanics, Faculty of mechanical engineering, University of Žilina, \\ Univerzitná 8215/1, 01026 Žilina, Slovak Republic
}

\begin{abstract}
In this paper, an effort has been put to analyze the rolling ball bearing using finite element analysis the contact pressure level, stress or displacement behavior of rolling ball bearing. The obtained results were then compared with the analytical results obtained through the methodology of Hertz theory in order to demonstrate an almost identical similarity of results and correct setting up of the given simulation in computational software ANSYS Workbench.
\end{abstract}

Keywords: Static structural analysis, Contact, Hertz theory, ANSYS Workbench.

\section{Introduction}

Rolling bearings are among the most important components of conveyor belts, working machines or various rotary mechanical applications and, therefore, the trend of increasing demands in terms of their production, accuracy, load-bearing capacity and reliability is increasing.

Their application lies in all branches of industry, from the production of heavy duty machinery in mining and stamping, in all modes of transport or in automotive or aviation, to the application of miniature bearings to high speed dental drills.

First of all, who drew and invented the ball-bearings was Leonardo da Vinci around the year 1500 . He designed the ball bearings to be incorporated into his design for the helicopter - it would make rotating the large screw on top much easier by reducing the friction by several orders of magnitude [9]. Philip Vaughan invented the ball bearing in the year 1794, it was 294 years after Leonardo's design. Vaughan's patent described how iron balls could be placed between the wheel and the axle and carriage. The balls let the carriage wheels rotate freely by reducing friction. Later, in August 1869, Parisian bicycle mechanic Jules Suriray received the first French patent for ball bearings. The bearings were then fitted to the winning bicycle ridden by James Moore in the world's first bicycle road race. The modern, selfaligning design of the ball bearing is attributed to Sven Wingquist of the SKF ball-bearing manufacturer in 1907. In the year 2002 INA/FAG established by Dr. Georg Schaeffler and Dr. Wilhelm Schaeffler E1 spherical ball and roller bearing, which is base of current, modern rolling bearings.

\footnotetext{
* Corresponding author: Peter.Sulka@fstroj.uniza.sk

Reviewers: Josef Soukup, Robert Grega
} 
Rolling bearings allow for the transfer of forces between the moving and fixed parts of the mechanical system and are designed to minimize friction arising from power and energy transfer.

Due to their multiple use, increasing emphasis is placed on their development and improvement, because in many cases the bearings do not provide the required durability according to the calculation values. There may be many reasons, for example, overload, load lower than required, inadequate lubrication, ineffective sealing, inadequate over fitting, or impact load on the bearing that leads to permanent deformation in the form of imprints in the bearing ring path paths. This very latest case of damage is becoming more and more frequent, for example automobile chassis bearings and it is necessary to examine the problem in order to examine the given load condition using the FEM method and to obtain optimal results for further research and modification of bearings with the intention of eliminating impact damage. Researchers still continue with the intensive development and research in field of rolling bearings with purpose to investigate new theory of bearing aspects, solving significant parameters and values of rolling bearings in order to ensure maximum quality and accurate prediction.

\section{Hertz theory}

In the elastic area, it is possible to calculate the contact pressure and the resulting deformation at the contact points of the rolling elements and orbits by means of Hertz theory. concerning to the contact of the volume elastic bodies. The general conclusions of this theory are based on three main assumptions.

1. The material of the bodies to be touched must be homogeneous and isotropic.

2. Only normal stress, not shear, can be transmitted in the contact area.

3. The proportional limit of the material must not be exceeded, that is, there can be no plastic deformation [1].

The contact area of the point contact of the load between the two curved bodies in point contact is generally elliptical (see Fig. 1). The elliptical contact surface for two components with identical elastic modulus E and Poisson constant is defined according to Hertz theory with respect to the main axis.

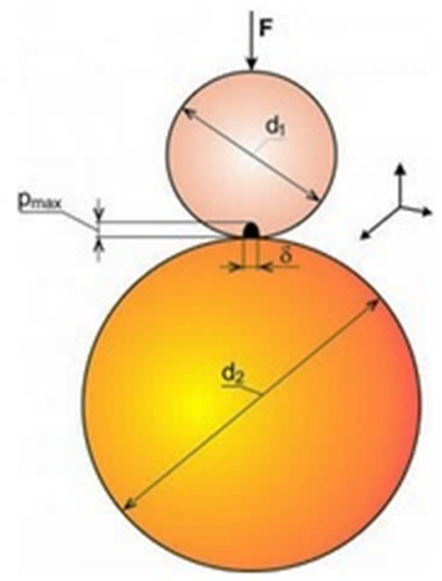

Fig. 1. Example illustrating the IMPACT function 
From the Fig. 1 is possible to detect significant parameter $\delta$, which is defined as wide of contact area. In case of point contact, the maximum contact pressure (see Fig. 2) is situated in the middle of contact area with appropriate value defined by following equation [2].

$$
p_{\max }=1.5 * \frac{F}{\frac{\pi}{4} \delta^{2}}
$$

$p_{\text {max }}$ is the maximum contact pressure [MPa],

$F$ is the external load [N],

$\delta$ is the wide o contact area $[\mathrm{mm}]$.

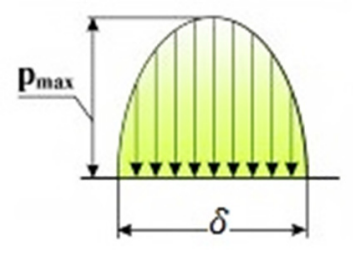

Fig. 2. The elliptical contact pressure

\section{Computation of contact pressure based on Hertz theory}

The stress calculation was performed using the following relationships dependent on bearing parameters, external load and mathematical coefficients. External load was defined for value $40000 \mathrm{~N}$ according to the empirical formula of curb-impact of specific ball bearings (see Fig. 3).

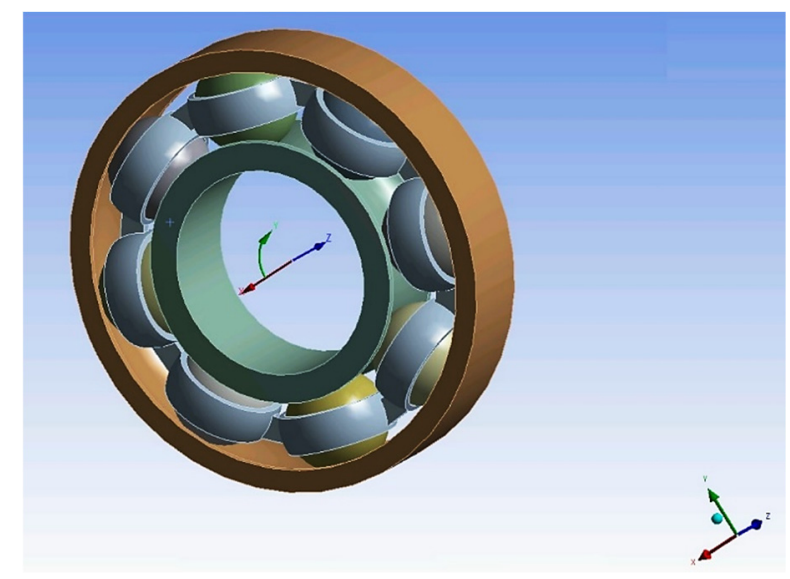

Fig. 3. 3D geometry of analysed rolling ball bearing

$$
F r_{\max }=\frac{4.37 * F}{Z}=\frac{4.37 * 40}{8}=21.85 \mathrm{kN}
$$

$F r_{\text {max }}$ is the maximum radial load of the rolling element [N],

$F$ is the size of the external radial load [N],

$Z$ is the number of rolling elements [-],

4.37 is the Striebeck coefficient for single row ball bearings [-] [10]. 


$$
F_{n}=\frac{F r_{\max }}{\cos (\alpha)}=\frac{21.85}{2 * \cos (45)}=15.45 k N
$$

$F_{n}$ is the maximum normal load [N],

$\alpha$ is the value of contact angle $\left[{ }^{\circ}\right]$.

$$
Q_{\max }=F_{n}=15.45 \mathrm{kN}
$$

$Q_{\max }$ is the maximum normal load of rolling element [MPa].

$$
\sigma_{\max }=4.37 * \varepsilon_{\sigma} *\left(\frac{Q \max }{d e^{2}}\right)^{\frac{1}{2}}=4.37 * 40.4686 *\left(\frac{15450}{6^{2}}\right)^{\frac{1}{2}}=3663.62 \mathrm{MPa}
$$

$\sigma_{\text {max }}$ is the maximum contact pressure according to the Hertz theory [MPa],

$d_{e}$ is the diameter of rolling element [mm],

$\varepsilon_{\sigma}$ is the empirical coefficient of contact pressure [-] [3].

From these empirical relations, the maximum contact pressure was determined to the value $\sigma_{\max }=3663.62 \mathrm{MPa}$.

\section{Computation of contact pressure based on finite element method}

The FEM analysis was performed in ANSYS Workbench. The simulation of the investigated bearing was solved as a linear model with given material properties of linear structural steel $\mathrm{E}=210,000 \mathrm{MPa}, \mu=0.3$.

The contact pairs have been customized between the individual roller elements and rings as well as the cage through the contact region function. The contact between the elements was given as friction contact $\mathrm{f}=0.05$, with a normal stiffness factor of 0.1 and was defined by the Lagrange formula $[3,8]$.

The boundary conditions of the bearing have been specified for each part as follows:

The outer ring and also inner ring displacement was removed in the z-axis direction and allowed in the direction of the $\mathrm{x}$ and $\mathrm{y}$ axes in the global Cartesian coordinate system. In the cylindrical global coordinate system, the displacement of the outer ring was taken in the ydirection and allowed in the $\mathrm{x}$-axis and $\mathrm{z}$-axis directions. In the cylindrical global coordinate system, the bead and cage displacement was taken in the $\mathrm{x}$ direction and allowed in the $\mathrm{y}$ and $\mathrm{z}$ direction. The coordinate systems are marked in previous figure (see Fig. 3).

External load was set with value $40000 \mathrm{~N}$ as Bearing Load in the negative y-axis direction with a bearing time of one second for simulation of impact load (see Fig. 4). 


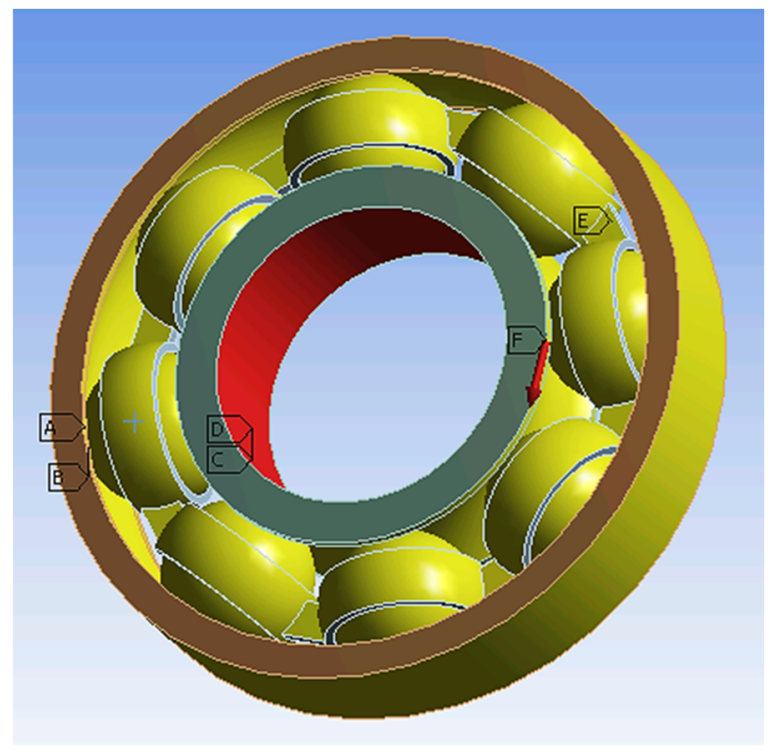

Fig. 4. The boundary conditions of investigated ball bearing

The results of performed FEM analysis with purpose to right investigate and compare analytical and numerical solution of contact characteristics display following figures.

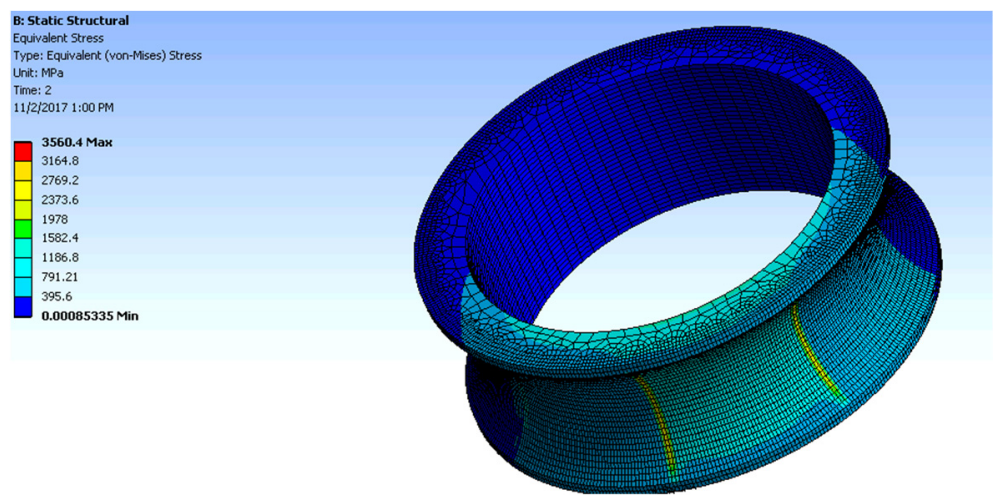

Fig. 5. Equivalent von-Mises Stress

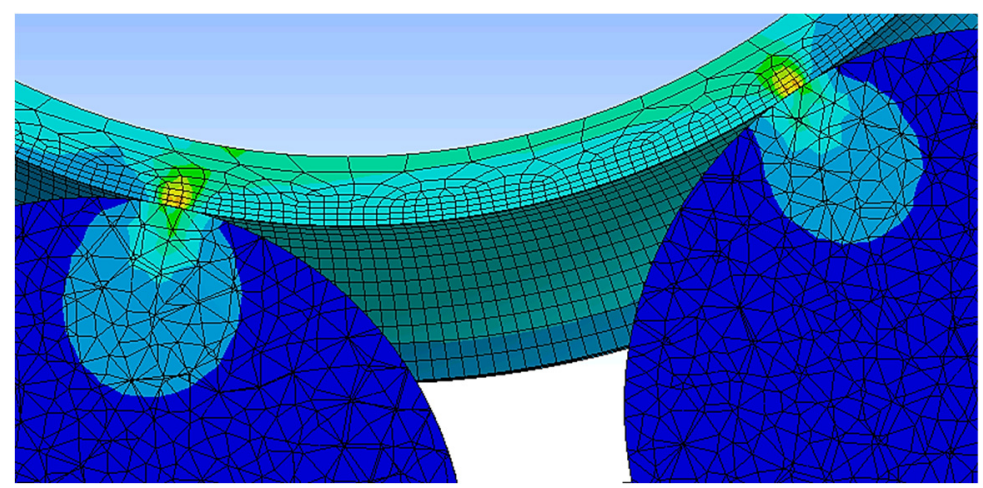

Fig. 6. Equivalent von Mises Stress in the cut 
From the previous figures (see Fig. 5, 6) is clearly possible to determine value of Equivalent von Mises stress on different parts of investigated rolling bearings. Accordingly is permited to see the elliptical shape of contact areas adn also under surface stresses. Equivalent von-Mises Stress is often used in design work because it allows any arbitrary three-dimensional stress state to be represented as a single positive stress value. Equivalent stress is part of the maximum equivalent stress failure theory used to predict yielding in a ductile material. Equivalent stress is related to the principal stresses by the following equation $[4,6]$.

$$
\sigma_{e}=\left[\frac{\left(\sigma_{1}-\sigma_{2}\right)^{2}+\left(\sigma_{2}-\sigma_{3}\right)^{2}+\left(\sigma_{3}-\sigma_{1}\right)^{2}}{2}\right]^{1 / 2}
$$

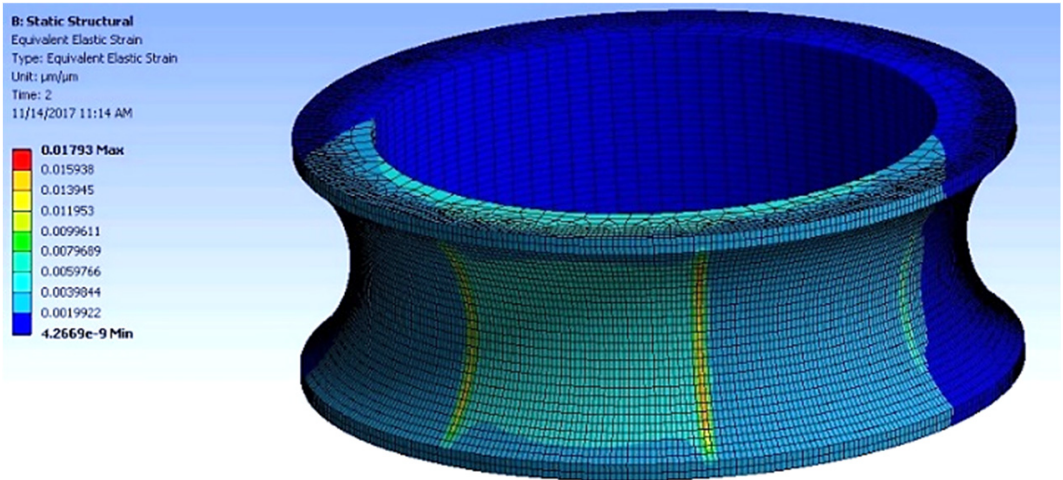

Fig. 7. Elastic deformation of inner ring

In the Fig. 7 is displayed the von Mises or equivalent strain $\varepsilon_{e}$ which is computed by next equation, where $\vartheta$ is effective Poisson's ratio [5,7].

$$
\varepsilon_{e}=\frac{1}{1+\vartheta}\left(\left[\left(\varepsilon_{1}-\varepsilon_{2}\right)^{2}+\left(\varepsilon_{2}-\varepsilon_{3}\right)^{2}+\left(\varepsilon_{3}-\varepsilon_{1}\right)^{2}\right]\right)^{1 / 2}
$$

From the following figures (see Fig. 8, 9), it is possible to detect the value of contact pressure, contact area and it's shave and as well penetration of rolling elements into orbital paths of bearing rings by the Contact Probe function of Post-processing function.

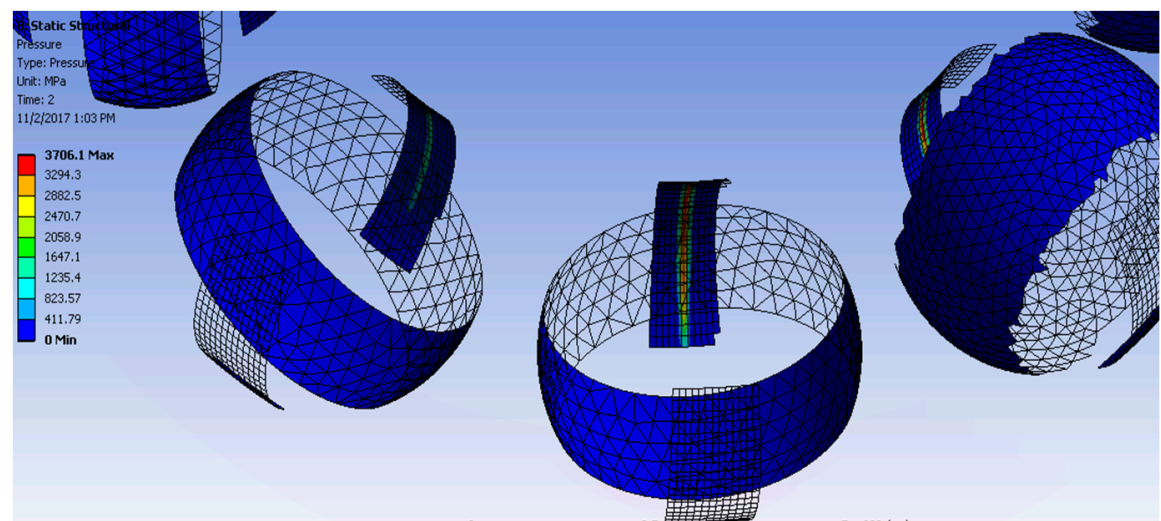

Fig. 8. Maximum contact pressure between rolling element and raceways 


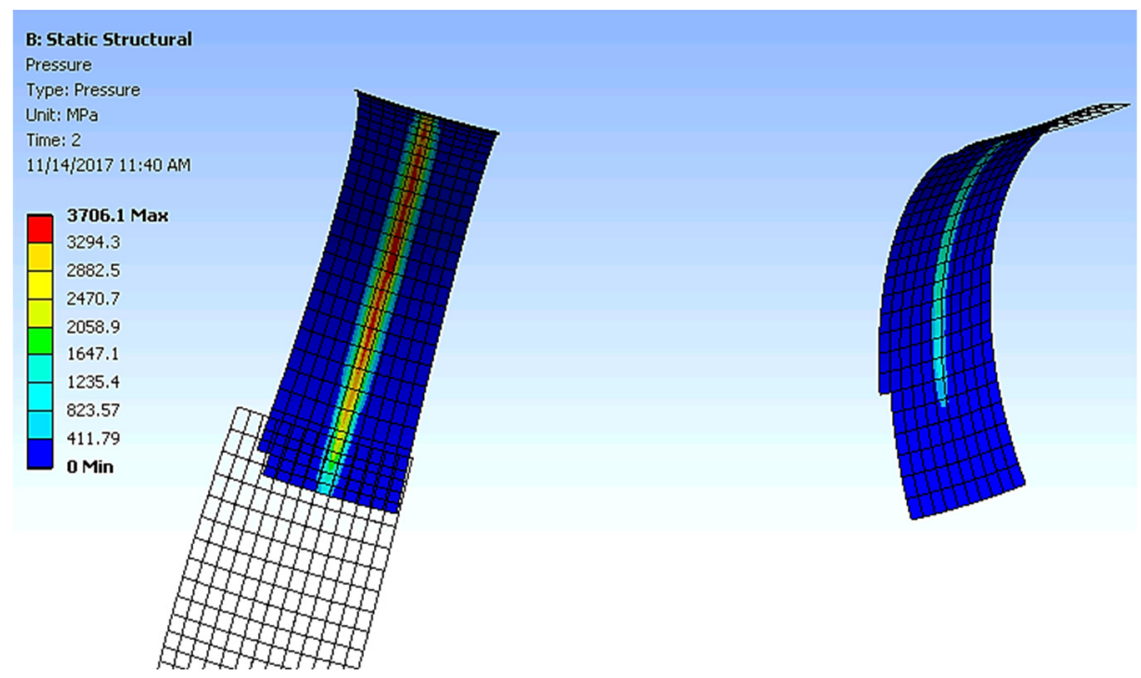

Fig. 9. The detail of contact pressure in contact areas

\section{Conclusion}

From the simulation and graphical outputs (see Fig. 5- 9), the results of the stress-strain analysis using the FEM software can be clearly seen. Through the analysis it was found that the value of the maximum contact pressure gets the size $\sigma_{\mathrm{FEM}}=3706.1 \mathrm{MPa}$ (see Fig. 9).

By comparing the results of the analytical and FEM (numerical) solutions, it can be detected that the results are almost identical.

$$
\sigma_{\max }=3663.62 \mathrm{MPa}==\sigma_{\mathrm{FEM}}=3706.1 \mathrm{MPa}
$$

The results of the MKP analysis are correct, which is proved by comparison of the analytical and numerical solution.

This paper was supported by VEGA 1/0795/16 and KEGA 017ŽU-4/2017.

\section{References}

1. P.K. Gupta, Computer graphics modeling of rolling bearing dynamics. Presented at the STLE Annual Meeting, Pittsburg, Pennsylvania (1994)

2. P.R. Anoopath, A.K. Vishwanath, Hertz contact stress of deep groove ball bearing. 7th Conference of materials processing and characterizaton, Published by Elsevier ltd., Vol. 5, No. 1, Pages 3283-3288 (2017)

3. T. Harris, Rolling Bearings Analysis. 4th Edition, John-Wiley \& Sons Inc., New York (2001)

4. H. Hertz, About the contact of elastic bodies. Collected Works, Vol.1, Leipzig, Germany (1960)

5. P. M. Johns, R. Gohar, Roller bearings under radial and eccentric loads. Tribology International, Vol. 14, No. 3, 131-136 (1981) 
6. A. B. Jones, A general theory for elastically constrained ball and radial bearings under arbitrary load and speed conditions. ASME Journal of Basic Engineering, 309-320 (1960)

7. V. Dekys, M. Sága, M. Žmindák, A.Hrčeková, Structural optimization by finite element method. Acta Mechanica Slovaca, 3-B2005, 61-67, (2005)

8. M. Žmindák, R. Melicher, V. Dekýš, FEM modeling and testing of cyclic plasticity of materials. Proceedings of the conference on occasion of 55th anniversary of foundation of the Faculty of Mechanical Engineering VSB - Technical University of Ostrava, 311316 (2005)

9. The ball bearing. Leonardo da Vinci's Ball Bearing. Accessable on the internet (http://www.leonardodavincisinventions.com/mechanical-inventions/leonardo-da-vinciball-bearing/)

10. H. Meerkmamm, Schaeffler Technical Pocket Guide, Schaeffler Technical Documentation (2014) 